\title{
Effects of Welding and rotational speeds on the Microstructure and Hardness of Friction Stir Welded Single-Phase Brass
}

\author{
Sajjad Emami • Tohid Saeid
}

Received: 7 September 2014/Revised: 2 February 2015/Published online: 27 March 2015

(C) The Chinese Society for Metals and Springer-Verlag Berlin Heidelberg 2015

\begin{abstract}
This study focuses on the effects of rotational and welding speeds on the microstructure and hardness of joints in friction stir welded single-phase brass. Welds were achieved under low heat input conditions at rotational and welding speeds of 400-800 r/min and 100-300 $\mathrm{mm} / \mathrm{min}$, respectively. In order to characterize the obtained welds, optical microscopy and Vickers hardness measurements were taken on the weld cross sections. According to the obtained results, increasing the welding speed and/or decreasing the rotational speed caused the grain size of the stir zone to decrease and, hence, improved the average hardness of this region. These results are discussed with respect to the interplay between the welding parameters and the peak temperature in the weld thermal cycle.
\end{abstract}

KEY WORDS: Friction stir welding; Single-phase brass; Dynamic recrystallization; Hardness

\section{Introduction}

Copper and copper alloys especially brasses constitute one of the major groups of commercial metals. They are widely used because of their excellent electrical and thermal conductivities, outstanding resistance to corrosion, ease of fabrication, and good strength and fatigue resistance $[1,2]$. However, welding of brasses is usually difficult by conventional processes of fusion welding because of the high thermal diffusivity of such materials, which is about 10-100 times higher than that of many steels and nickel alloys. The greater dissipation of heat within workpiece requires higher heat inputs as well as lower welding speeds [3-6]. The welding temperature, for example in the GTAW method, increases up to $4200{ }^{\circ} \mathrm{C}$ in the electrode and about $3200{ }^{\circ} \mathrm{C}$ in the workpiece while welding. These

Available online at http://link.springer.com/journal/40195

S. Emami · T. Saeid $(\bowtie)$

Materials Engineering Faculty, Sahand University of

Technology, Tabriz, Iran

e-mail: saeid@sut.ac.ir temperatures are much higher than the melting and boiling temperatures of the alloy. Therefore, it is possible for zinc and copper, the main constituents of brasses, to evaporate out of the workpiece during welding. The lower boiling temperature of the zinc in comparison with copper causes zinc to evaporate more than copper. As a result, the suitable chemical and mechanical properties of the base metal (BM) would deteriorate in the weld zone [7].

In order to prevent zinc evaporation, friction stir welding (FSW) could be considered as an alternative in joining of brasses. FSW is a relatively new solid-state technique developed by the Welding Institute (TWI) for joining of aluminum alloys. In this welding process, a rotating tool is inserted into the joint line of two adjoining materials and then translated along the interface $[6,8]$. The weld is formed by deformation and dynamic restoration of the material at temperatures below the melting temperature, which can potentially solve the problem of zinc evaporation. On the other hand, weld zone in the FSW does not have the dendritic structure which typically occurs in fusion welding [7]. In addition, FSW is essentially a process without large distortion, solidification cracking, porosity, and loss of alloying elements [6]. These interests encouraged many researchers 
to focus on FSW of $\mathrm{Cu}$ alloys. For example, Meran [7] investigated the effect of welding speed on the microstructure and hardness of friction stir welded single-phase brass at constant rotational speed of $2050 \mathrm{r} / \mathrm{min}$ and welding speeds within the range of $20-140 \mathrm{~mm} / \mathrm{min}$. It was found that zinc evaporation did not occur in weld zone due to solid-state nature of the FSW. Also, when appropriate welding speed of $112 \mathrm{~mm} / \mathrm{min}$ was used, joint mechanical properties were comparable with that of BM. Similar results were obtained by Moghaddam et al. [3], who studied the effect of welding speed on the microstructure and hardness of friction stir welded single-phase brass at constant rotational speed of $950 \mathrm{r} / \mathrm{min}$ and various welding speeds of $190-375 \mathrm{~mm} / \mathrm{min}$.

The mentioned researchers conducted valuable works in the FSW of brass at constant rotational speed, and the present work aims to complete these studies by considering both effects of welding and rotational speeds at relatively lower rotational speeds. Thus, the objectives of this study are to clarify the appropriate welding conditions for sound welds, the detail of microstructures and mechanical properties, and the correspondence between the mechanical properties and microstructural changes in a wide range of the welding parameters including low heat input conditions for single-phase brass.

\section{Experimental Procedure}

The material used in this study was a $\mathrm{Cu}-(33.8$ wt.\%) $\mathrm{Zn}$ alloy plate with chemical composition (wt.\%) of $66.15 \mathrm{Cu}$, 33.815 Zn, $0.008 \mathrm{Sn}, 0.01 \mathrm{~Pb}, 0.11 \mathrm{Fe}, 0.005 \mathrm{Ni}$, and $<0.002 \mathrm{~S}$.

Bead-on-plate welds were made by a single-pass FSW to find out the optimum conditions and associated mechanical properties and microstructural characteristics. The dimensions of the weld specimens were $330 \mathrm{~mm} \times$ $60 \mathrm{~mm} \times 2 \mathrm{~mm}$. These specimens were clamped tightly to a thick backing plate of low carbon steel. The welding tool was made from $\mathrm{H} 13$ hot work steel with the hardness of 52 RC. The tilt angle for all welds was kept constant at $3^{\circ}$. Figure 1 shows the FSW setup and welding tool geometry. Welding trials were conducted at tool rotational and welding speeds of $400-800 \mathrm{r} / \mathrm{min}$, and $100-400 \mathrm{~mm} / \mathrm{min}$, respectively.

Microstructural changes from the weld zone to the unaffected BM were examined with an optical microscope (OM). For optical microstructure observations, the cross section of weldments was polished and then etched with a solution of $50 \mathrm{~mL} \mathrm{H}_{2} \mathrm{O}, 2-5 \mathrm{~mL} \mathrm{HCl}$, and $5 \mathrm{~g} \mathrm{FeCl}_{3}$. The Vickers microhardness profiles of the weld zone were measured on a cross section perpendicular to the welding direction using a $0.5 \mathrm{~N}$ load for $10 \mathrm{~s}$.

\section{Results and Discussion}

\subsection{Appearances of the Welds}

The FSW conditions resulting in sound welds are summarized in Fig. 2. According to Fig. 2, tool pin fracture occurred at welding speed of $400 \mathrm{~mm} / \mathrm{min}$ with the rotational speeds of 400,600 , and $800 \mathrm{r} / \mathrm{min}$ and also at the welding speed of $300 \mathrm{~mm} / \mathrm{min}$ with rotational speed of $400 \mathrm{r} / \mathrm{min}$. Figure 3 shows the bead appearance of the sound welds. It can be seen that no observable defect was formed on weld surfaces.

\subsection{Macro- and Microstructures of Welds}

Figure 4 shows the cross-sectional macrographs of the welds associated with the welding conditions of this work. Depending on processing parameters, different shapes of weld nugget, which are basically categorized as basinshaped and the elliptical, have been observed. Similar results were observed in the FSW of pure copper in which both shapes were obtained by changing the welding conditions [9].

Based on microstructural observations, three distinct zones were detected as stir zone (SZ), thermomechanically affected zone (TMAZ), and base metal (BM). Figure 5 shows typical microstructures from BM in advancing side to the border of SZ/TMAZ in the retreating side. Similar to previous works of Sarvghad Moghaddam et al. [3] and Park et al. [10], no distinctive heat-affected zone (HAZ) was observed. However, it should be pointed out that Xie et al. $[11,12]$ identified a clear HAZ in FSW of thicker plates of dual-phase brass due to the transformation of $\beta^{\prime}$ phase to $\alpha$ phase. Existence of $\beta^{\prime}$ in the microstructure and higher amount of generated heat could justify that why in the latter case, which evidences of the HAZ were detected. It is obvious that equiaxed grains are formed in the SZ with grain sizes much smaller than that of the BM. It is well accepted in the literatures that generation of fine and equiaxed grains in the SZ is due to dynamic recrystallization [3-14]. Dynamic recrystallization is one of the main metallurgical phenomena, which controls the grain size. This phenomenon is frequently observed in metals during hot working [15]. It seems that severe plastic deformation and frictional heating during FSW cause a recrystallized fine grain structure to be formed. According to the general principles of recrystallization, dynamic recrystallization may occur either by continuous extended recovery processes through annihilation and rearrangement of dislocations or by a discontinuous formation of new, relatively dislocation-free grains through recrystallization. The operative mechanism depends on the strain and strain rate histories, as well as stacking fault energy (SFE) of the 

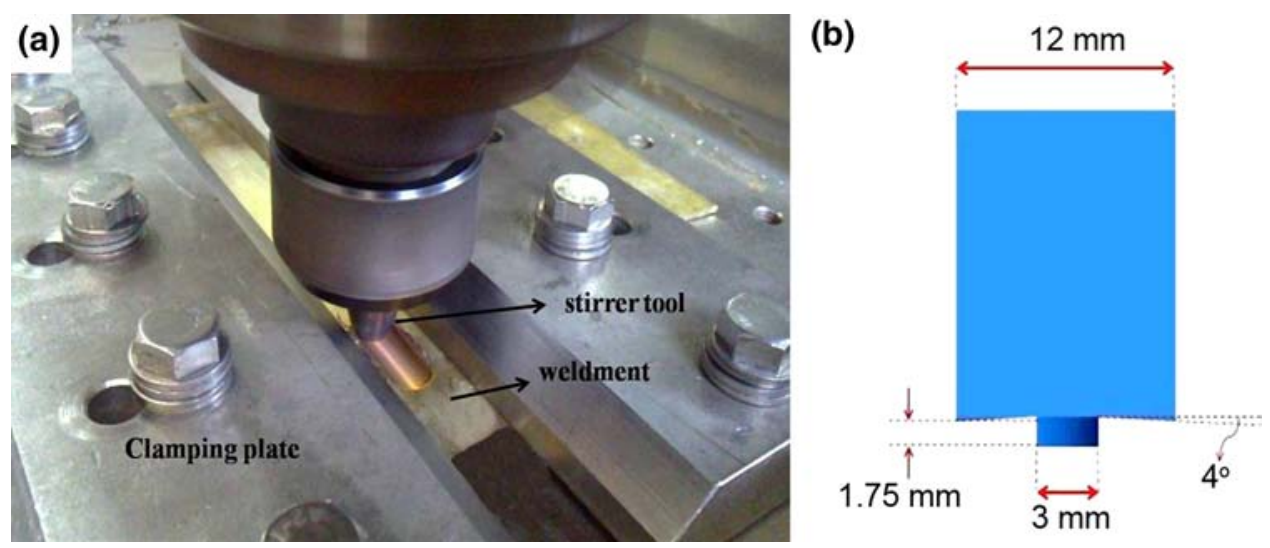

Fig. 1 a Friction stir welding setup; b schematic of the welding tool

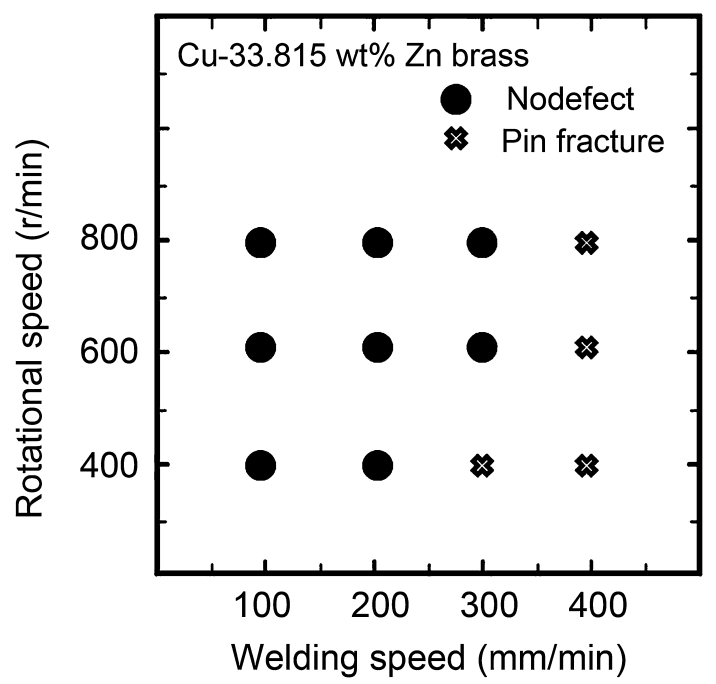

Fig. 2 Process window of the defect free welds

material. For a given material, higher stresses (or strains) and strain rates tend to promote discontinuous recrystallization. Moreover, materials with low SFE (such as austenitic stainless steels) generally undergo discontinuous dynamic recrystallization because the dissociation of the dislocations makes the recovery more difficult, while the materials with high SFE (such as ferritic stainless steels) tend to experience continuous dynamic recrystallization [15-17]. As the SFE of the alpha brass is much lower than that of pure copper [18], it seems to undergo the discontinuous dynamic recrystallization.

In the TMAZ, the area between the BM and the SZ, the material underwent both high temperature and deformation during FSW, but the strain was not much enough to cause the recrystallization [6]. As a result, grains were deformed and elongated (see Fig. 5c, e).

Figure 6 shows the variation in microstructures in the SZ associated with all welding conditions. It can be seen that grain size decreases as the rotational speed decreases

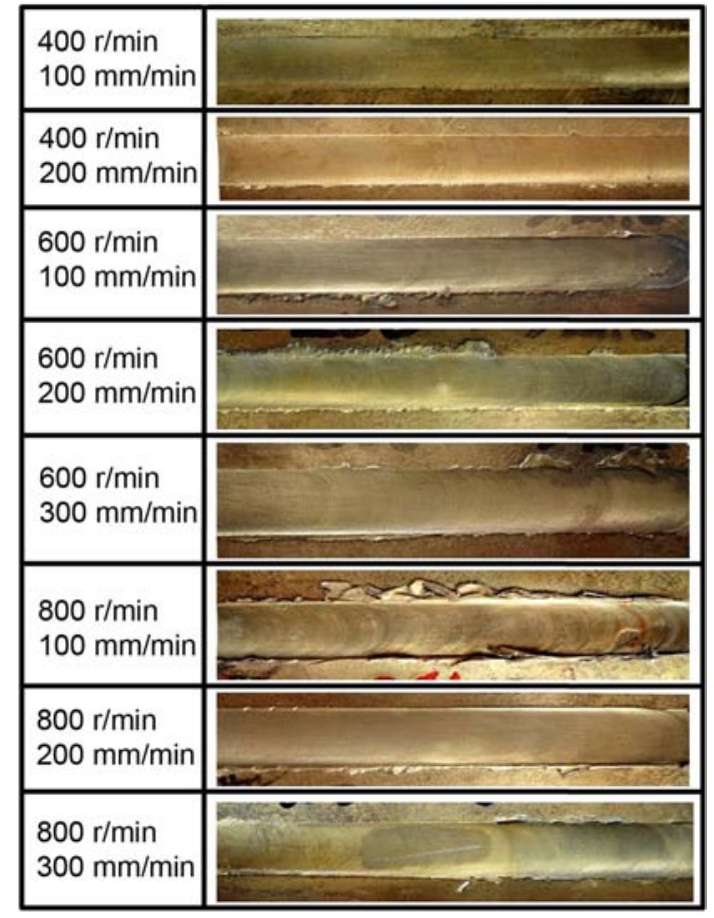

Fig. 3 Weld surface appearances at different welding conditions

or welding speed increases. The size of recrystallized grains in the SZ depends on two factors such as degree of deformation and the peak temperature obtained during FSW [3, 19]. A decrease in degree of plastic deformation causes the recrystallized grain size to increase, and the decrease in peak temperature decreases the grain size of the SZ $[6,16]$. Accordingly, it can be concluded from Fig. 6 that peak temperature of weld thermal cycle may be the dominant factor in determining the grain size. These findings are in conformance with the literature $[9,10,19]$.

The total heat input generated by the FSW, which affects the grain size, can be simply expressed through the following equation [15]: 


\begin{tabular}{|c|c|}
\hline $\begin{array}{l}400 \mathrm{r} / \mathrm{min} \\
100 \mathrm{~mm} / \mathrm{min}\end{array}$ & 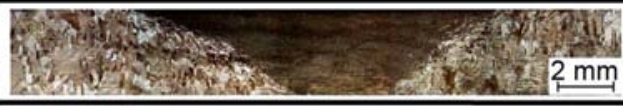 \\
\hline $\begin{array}{l}400 \mathrm{r} / \mathrm{min} \\
200 \mathrm{~mm} / \mathrm{min}\end{array}$ & 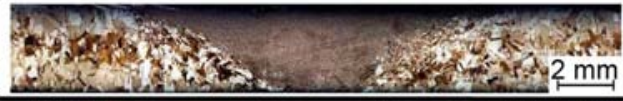 \\
\hline $\begin{array}{l}600 \mathrm{r} / \mathrm{min} \\
100 \mathrm{~mm} / \mathrm{min}\end{array}$ & 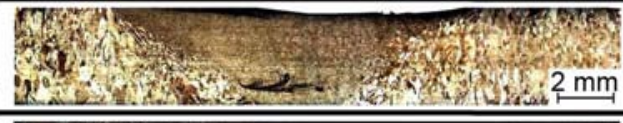 \\
\hline $\begin{array}{l}600 \mathrm{r} / \mathrm{min} \\
200 \mathrm{~mm} / \mathrm{min}\end{array}$ & 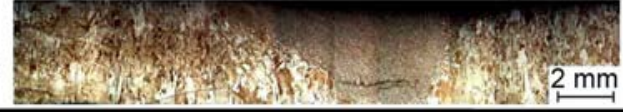 \\
\hline $\begin{array}{l}600 \mathrm{r} / \mathrm{min} \\
300 \mathrm{~mm} / \mathrm{min}\end{array}$ & 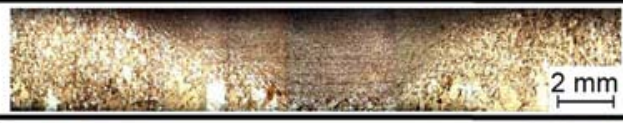 \\
\hline $\begin{array}{l}800 \mathrm{r} / \mathrm{min} \\
100 \mathrm{~mm} / \mathrm{min}\end{array}$ & 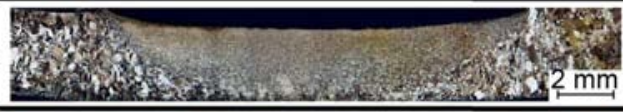 \\
\hline $\begin{array}{l}800 \mathrm{r} / \mathrm{min} \\
200 \mathrm{~mm} / \mathrm{min}\end{array}$ & 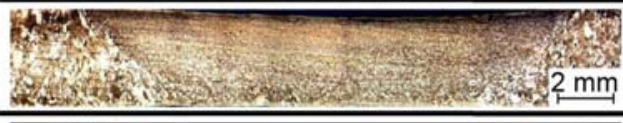 \\
\hline $\begin{array}{l}800 \mathrm{r} / \mathrm{min} \\
300 \mathrm{~mm} / \mathrm{min}\end{array}$ & 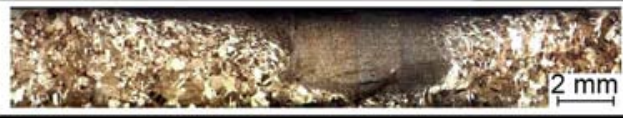 \\
\hline
\end{tabular}

Fig. 4 Cross-sectional macrostructure of welds at different welding conditions

$Q=\frac{4}{3} \pi^{2} \frac{\eta \mu R_{\mathrm{s}} \operatorname{Pr}^{3}}{W_{\mathrm{s}}}$

where $Q$ is the heat input, $\eta$ is heat efficiency, $\mu$ is friction coefficient, $P$ is vertical pressure, $r$ is radius of the shoulder, $R_{\mathrm{s}}$ is rotational speed, and $W_{\mathrm{s}}$ is the welding speed. According to this equation, as $W_{\mathrm{s}}$ is decreased or $R_{\mathrm{S}}$ increased, $Q$ increases, and therefore, higher peak temperature at lower welding speed (and or higher rotational speed) is resulted, which in turn causes coarser grain size in the SZ (see Fig. 6). Similar behavior was observed by Park et al. [10] in FSW of $60 \mathrm{wt} . \% \mathrm{Cu}-40 \mathrm{wt} . \% \mathrm{Zn}$ alloy at constant traverse speed by decreasing the rotational speed.

Figure 7 shows typical variation in microstructure from top to bottom in the center of the SZ. The grain size within the weld zone tends to decrease near the top of the weld zone. It seems that the material near the tool shoulder received greater amount of strain with respect to the material away from the tool shoulder. In all welding conditions, top part of the SZ had the smaller grain size than other parts of the weld. The observed gradient of microstructural refinement is consistent with the development of strain gradient as a function of distance from the tool shoulder [14].

\subsection{Effect of Welding Conditions on Hardness of the Welds}

Figure 8 shows the typical hardness profile along the centerline on cross section of the weld in the condition of $800 \mathrm{r} / \mathrm{min}$ and $100 \mathrm{~mm} / \mathrm{min}$. As it is demonstrated, the hardness value increases in the SZ. All samples have the same behavior in the SZ. Such behavior is due to the generation of extremely fine grains in the SZ.

Furthermore, variation in SZ average hardness at various welding conditions is shown in Fig. 9. The hardness tends (a)

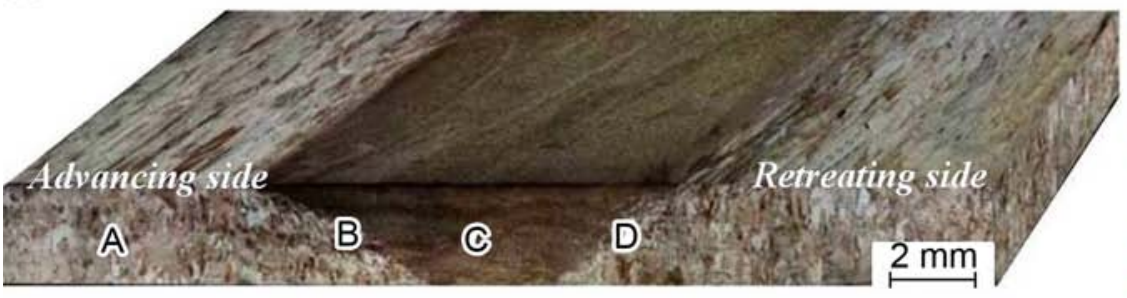

(c)

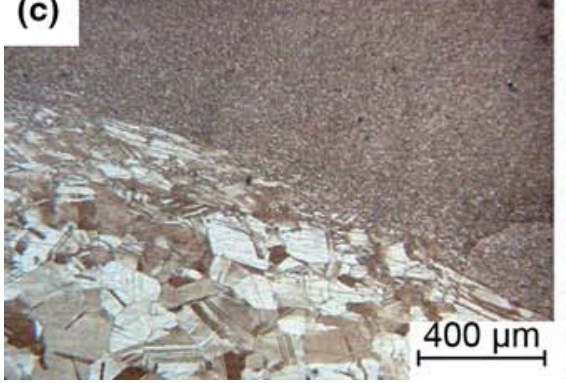

(d)

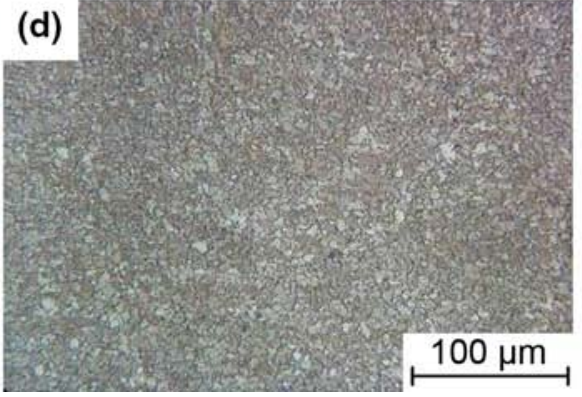

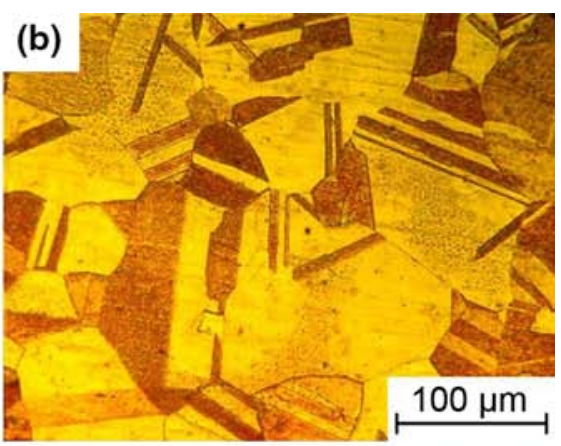

(e)

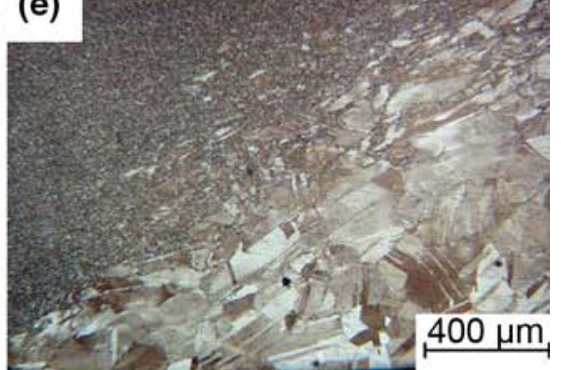

Fig. 5 Optical macrographs of brass after FSW (400 r/min, $100 \mathrm{~mm} / \mathrm{min}$ ): a overall 3D macrograph; b BM region, labeled by $A$; c TMAZ/SZ border in the advancing side, labeled by $B ; \mathbf{d}$ SZ region, labeled by $C$; d SZ/TMAZ border in the retreating side of weld, labeled by $D$ 

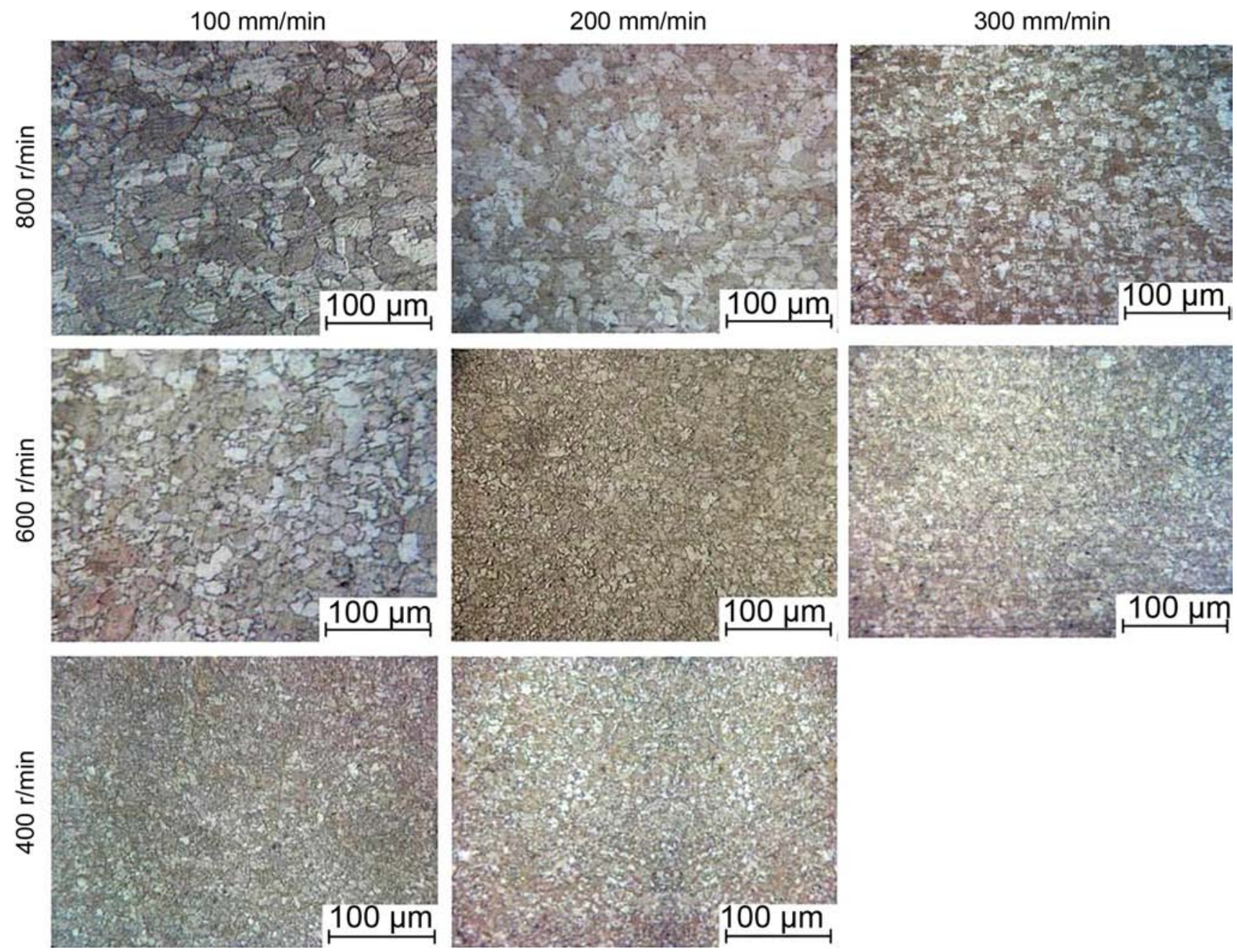

Fig. 6 Variation in SZ microstructures at different welding conditions
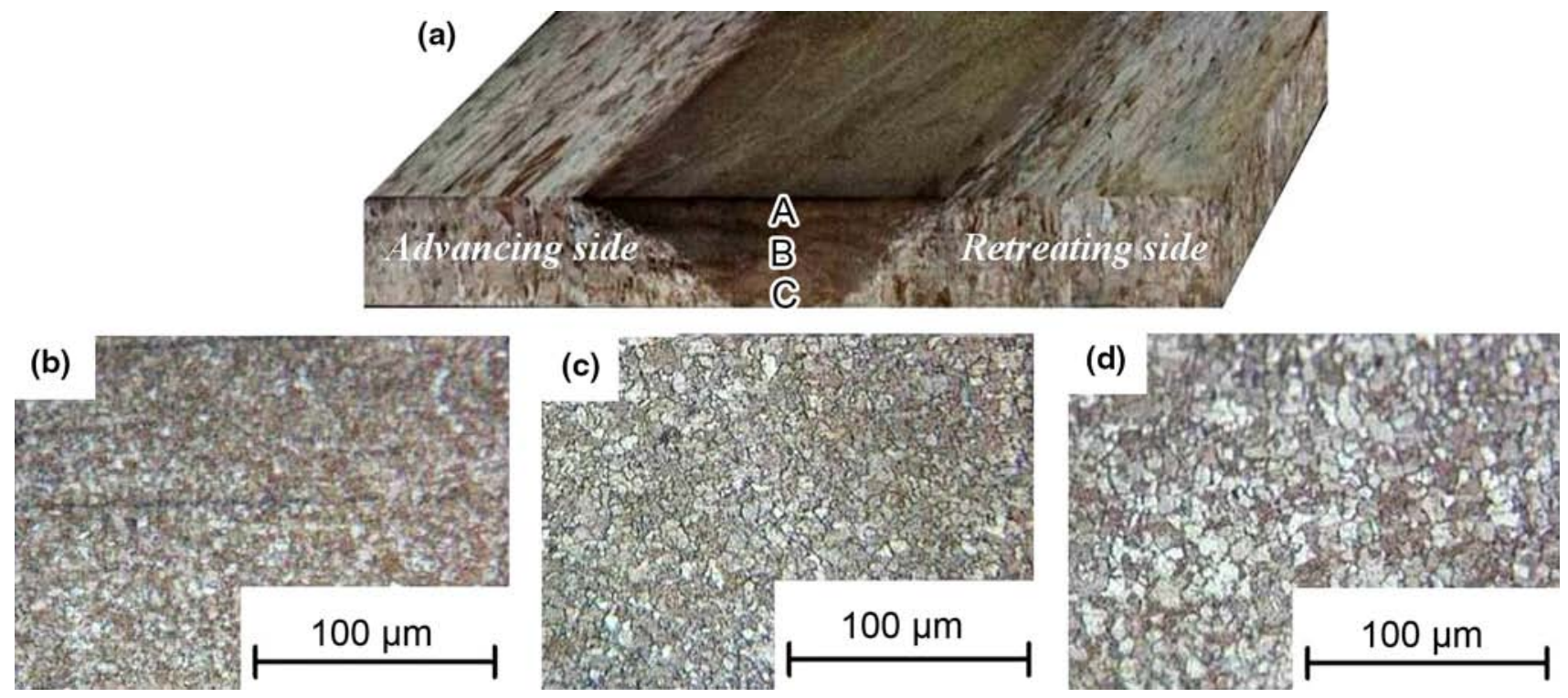

Fig. 7 Microstructure variation in weld center from the top a to the bottom $\mathbf{c}$ of $400 \mathrm{r} / \mathrm{min}, 100 \mathrm{~mm} / \mathrm{min}$ sample: a overall view of weld center; b top region, labeled by $A$; $\mathbf{c}$ middle region, labeled by $B$; $\mathbf{d}$ bottom region, labeled by $C$ 


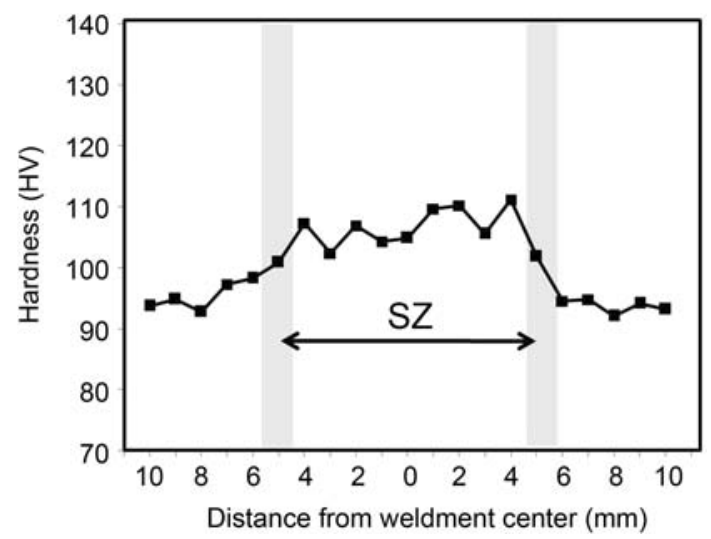

Fig. 8 Hardness profiles in cross section of the weld

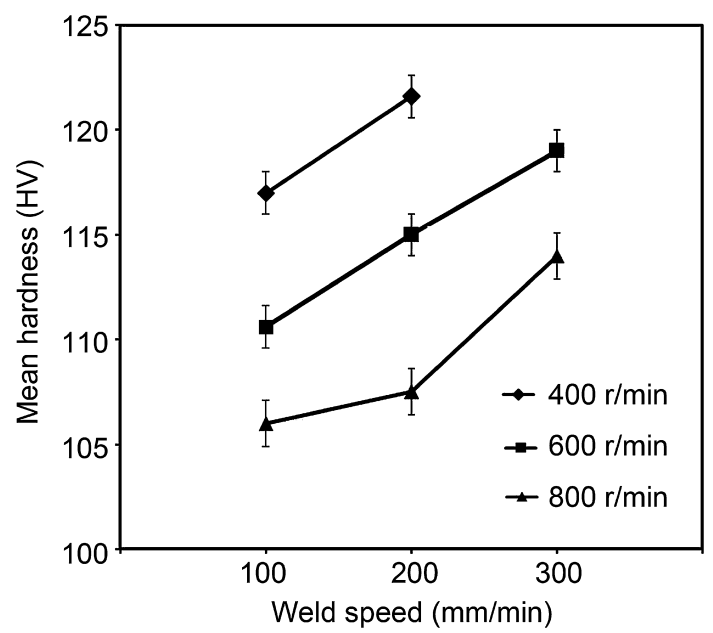

Fig. 9 Variation in hardness in the SZ for all welding conditions

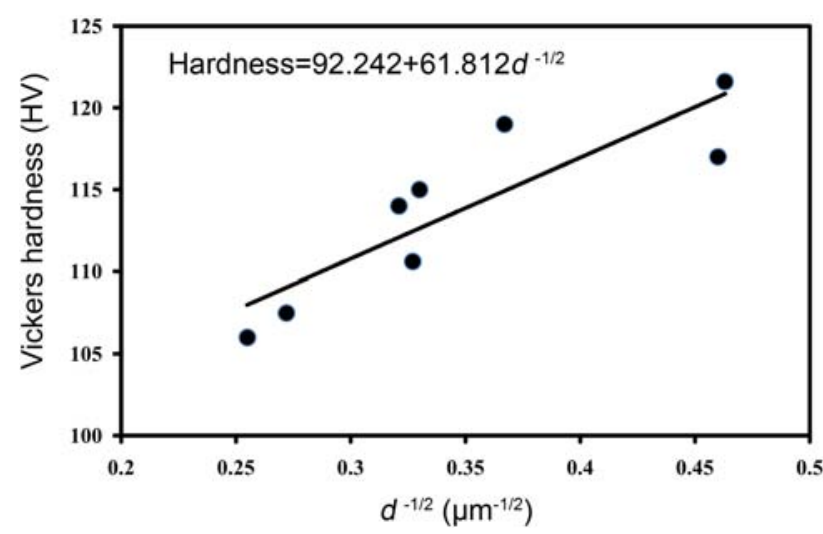

Fig. 10 Variation in hardness with grain size in FSW of single-phase brass

to increase with an increase in welding speed or decrease in rotational speed. It is considered that the variation in hardness is related to the microstructural changes in the SZ induced by welding conditions. As described above in Fig. 6, the higher welding speed or lower rotational speed leads to the formation of smaller grains in the SZ. This is the reason why the hardness monotonically increases by increasing welding speed at constant rotational speeds. Variation in hardness with grain size was identified to follow the Hall-Petch relationship (Fig. 10).

\section{Conclusions}

In summary, FSW of a single-phase brass was performed at different welding conditions. Except for rotational and welding speeds of $400 \mathrm{r} / \mathrm{min}$ and $300 \mathrm{~mm} / \mathrm{min}$, respectively, sound joints were achieved under rotational speeds of $400-800 \mathrm{r} / \mathrm{min}$ and welding speeds of $100-300 \mathrm{~mm} /$ min. The microstructure in the SZ consisted of fine equiaxed grains, and their sizes decreased with increasing welding speed and/or decreasing rotational speed. This behavior could be as a result of welding at lower heat input conditions and dynamic recrystallization at lower peak temperatures. Moreover, due to the variations in grain size, hardness of the SZ decreased by increasing the rotational speed and increased by increasing the welding speed.

\section{References}

[1] H.S. Kim, W.Y. Kim, K.H. Song, J. Alloys Compd. 536, S200 (2012)

[2] Sh Li, H. Imai, K. Kondoh, A. Kojima, Y. Kosaka, K. Yamamoto, Mater. Chem. Phys. 135, 644 (2012)

[3] M. Sarvghad Moghaddam, R. Parvizi, M. Haddad-Sabzevar, A. Davoodi, Mater. Des. 32, 2749 (2011)

[4] H. Khodaverdizadeh, A. Heidarzadeh, T. Saeid, Mater. Des. 45, 265 (2013)

[5] J.J. Shen, H.J. Liu, F. Cui, Mater. Des. 31, 3937 (2010)

[6] R.S. Mishra, Z.Y. Ma, Mater. Sci. Eng. R 50, 1 (2005)

[7] C. Meran, Mater. Des. 27, 719 (2006)

[8] D. Wang, B.L. Xiao, D.R. Ni, Z.Y. Ma, Acta Metall. Sin. (Engl. Lett.) 27, 816 (2014)

[9] G.M. Xie, Z.Y. Ma, L. Geng, Scr. Mater. 57, 73 (2007)

[10] H.S. Park, T. Kimura, T. Murakami, Y. Nagano, K. Nakata, M. Ushio, Mater. Sci. Eng. A 371, 160 (2004)

[11] G.M. Xie, Z.Y. Ma, L. Geng, Mater. Trans. 49, 1698 (2008)

[12] G.M. Xie, Z.Y. Ma, L. Geng, Philos. Mag. 89, 1505 (2009)

[13] T. Saeid, A. Abdollah-zadeh, T. Shibayanagi, K. Ikeuchi, H. Assadi, Mater. Sci. Eng. A 527, 6484 (2010)

[14] W.B. Lee, S.B. Jung, Mater. Lett. 58, 1041 (2004)

[15] H. Hallberg, M. Wallin, M. Ristinmaa, Compos. Mater. Sci. 49, 25 (2010)

[16] F.J. Humphreys, M. Hatherly, Recrystallization and Related Annealing Phenomena, 2nd edn. (Pergamon Press, New York, 2004)

[17] T. Saeid, A. Abdollah-zadeh, H. Assadi, F. Malek Ghaini, Mater. Sci. Eng., A 496, 262 (2008)

[18] M. Hafok, R. Pipan, Int. J. Mater. Res. 101, 1097 (2010)

[19] K. Surekha, A. Els-Botes, Mater. Des. 32, 911 (2011) 